Magazine of Concrete Research Volume 65 issue 3

Prestressed concrete thermal behaviour Aslani
Magazine of Concrete Research, 2013, 65(3), 158-171 i

\title{
Prestressed concrete thermal behaviour
}

\section{Farhad Aslani}

Centre for Built Infrastructure Research, School of Civil and Environmental Engineering, University of Technology, Sydney, Australia

The structural fire safety capacity of concrete is very complicated because concrete materials have considerable variations. Constitutive relationships for prestressed normal-strength concrete (NSC) and high-strength concrete (HSC) subjected to fire are needed to provide efficient modelling and to meet specific fire-performance criteria of the behaviour for prestressed concrete structures exposed to fire. In this paper, formulations for estimating the parameters affecting the behaviour of unconfined prestressed concrete at high temperatures are proposed. These formulations include residual compression strength, initial modulus of elasticity, peak strain, thermal strain, transient creep strain and the compressive stress-strain relationship at elevated temperatures. The proposed constitutive relationships are verified with available experimental data and existing models. The proposed relationships are general and rational, and show good agreement with the experimental data. More tests are needed to further verify and improve the proposed constitutive relationships.

\begin{tabular}{|c|c|}
\hline Notation & \\
\hline$C_{1}, C_{2}, C_{3}$ & $\begin{array}{l}\text { constants to account for aggregate type in } \\
\text { evaluating transient creep strain }\end{array}$ \\
\hline$E_{\mathrm{c}}$ & $\begin{array}{l}\text { initial modulus of elasticity at ambient } \\
\text { temperature }\end{array}$ \\
\hline$E_{\mathrm{crT}}$ & $\begin{array}{l}\text { initial modulus of elasticity at elevated } \\
\text { temperature }\end{array}$ \\
\hline$E_{\mathrm{p}}$ & secant modulus of elasticity \\
\hline$f_{\mathrm{ci}}$ & initial compressive stress before heating \\
\hline$f_{\mathrm{c}}^{\prime}$ & $\begin{array}{l}\text { concrete compressive strength at ambient } \\
\text { temperature }\end{array}$ \\
\hline$f_{\mathrm{cT}}^{\prime}$ & $\begin{array}{l}\text { concrete compressive stress at elevated } \\
\text { temperature }\end{array}$ \\
\hline$g$ & $\begin{array}{l}\text { function to account for increase in modulus of } \\
\text { elasticity due to external loads }\end{array}$ \\
\hline$k_{\mathrm{tr}}$ & $\begin{array}{l}\text { constant }(1 \cdot 8-2 \cdot 35) \text { used to evaluate transient } \\
\text { creep strain }\end{array}$ \\
\hline$T$ & fire temperature in ${ }^{\circ} \mathrm{C}\left(\geqslant 20^{\circ} \mathrm{C}\right)$ \\
\hline$T_{1}, T_{2}, T_{8}, T_{64}$ & $\begin{array}{l}\text { constants describing the reduction in the } \\
\text { concrete compressive strength for different } \\
\text { aggregate types }\end{array}$ \\
\hline$t$ & age of concrete \\
\hline$V_{\mathrm{a}}$ & $\begin{array}{l}\text { volume fraction of aggregate used to evaluate } \\
\text { the transient creep strain }\end{array}$ \\
\hline$\alpha$ & thermal expansion coefficient \\
\hline$\gamma_{\mathrm{o}}$ & $\begin{array}{l}\text { constant to account for aggregate type in } \\
\text { evaluating transient creep strain }\end{array}$ \\
\hline$\gamma_{\mathrm{w}}$ & $\begin{array}{l}\text { function to account for the effect of moisture } \\
\text { content on transient creep strain }\end{array}$ \\
\hline$\varepsilon_{0 \cdot 3}$ & $\begin{array}{l}\text { transient creep strain for initial stress of } \\
0 \cdot 3 f_{\mathrm{c}}^{\prime}\end{array}$ \\
\hline
\end{tabular}

\begin{tabular}{|c|c|}
\hline$\varepsilon_{\mathrm{cT}}$ & concrete strain at elevated temperature \\
\hline$\varepsilon_{\mathrm{cu}}$ & $\begin{array}{l}\text { ultimate strain for concrete at ambient } \\
\text { temperature }\end{array}$ \\
\hline$\varepsilon_{\max }$ & $\begin{array}{l}\text { strain at maximum stress of concrete at } \\
\text { elevated temperature }\end{array}$ \\
\hline$\varepsilon_{\mathrm{th}}$ & unrestrained thermal strain \\
\hline$\varepsilon_{\mathrm{tr}}$ & transient creep strain \\
\hline$\varepsilon_{\mathrm{tu}}$ & cracking strain \\
\hline$\varepsilon_{\mathrm{c}}^{\prime}$ & $\begin{array}{l}\text { strain at maximum stress for concrete at } \\
\text { elevated temperature }\end{array}$ \\
\hline$\varepsilon_{\mathrm{c} 1}^{\prime}, \varepsilon_{\mathrm{c} 2}^{\prime}, \varepsilon_{\mathrm{c} 3}^{\prime}$ & $\begin{array}{l}\text { strain at maximum stress as a function of } \\
\text { temperature for } 0 \%, 10 \% \text { and } 20 \% \text { initial stress } \\
\text { level }\end{array}$ \\
\hline$\eta_{\mathrm{mT}}$ & $\begin{array}{l}\text { material parameter that depends on the shape } \\
\text { of the stress-strain curve }\end{array}$ \\
\hline$\eta_{\mathrm{mT}, \mathrm{a}}$ & $\begin{array}{l}\text { modified material parameter at the ascending } \\
\text { branch at elevated temperature }\end{array}$ \\
\hline$\eta_{\mathrm{mT}, \mathrm{d}}$ & $\begin{array}{l}\text { modified material parameter at descending } \\
\text { branch at elevated temperature }\end{array}$ \\
\hline$\lambda$ & coefficient of linear equation \\
\hline$\lambda_{\mathrm{L}}$ & $\begin{array}{l}\text { factor accounting for the initial compressive } \\
\text { stress level }\end{array}$ \\
\hline$\sigma_{\mathrm{cT}}$ & $\begin{array}{l}\text { concrete compressive stress at elevated } \\
\text { temperature }\end{array}$ \\
\hline$\phi$ & function to evaluate transient creep strain \\
\hline
\end{tabular}

\section{Introduction}

The behaviour of concrete structures exposed to extreme thermomechanical loading is an issue of great importance in nuclear engineering. The design of fire-resistant structural elements requires realistic knowledge of the behaviour of concrete at high 
temperatures. The fire resistance of concrete can be determined by three test methods available for finding the residual compressive strength of concrete at elevated temperatures: the stressed test, unstressed test and unstressed residual strength test. The stressed and unstressed tests are suitable for assessing the strength of concrete at high temperatures, while the unstressed residual strength test is excellent for finding the residual properties after a period of elevated temperature. In the stressed test, specimens are restrained by a preload prior to and throughout the heating process. In the unstressed test, specimens are heated without restraint. Both stressed and unstressed specimens are loaded to failure under uniaxial compression when the steady-state temperature is reached at the target level. The unstressed residual property test method is designed to provide property data for concrete at room temperature after exposure to elevated temperatures (Husem, 2006; Phan and Carino, 2003).

Creep can be defined as the time-dependent strain response of a material to loading. Basic creep has been defined as the loadinduced, time-dependent deformation of a specimen that is loaded after achieving thermal, hygral, chemical and dimensional stability at first heating to a given temperature. The creep of specimens that are loaded after achieving stability at temperatures higher than the temperature at loading can also, albeit loosely, be termed basic creep. The effects of temperature on the creep of hardened cement paste can be broadly classified as thermal and structural. The thermal effect is that due to the temperature at loading, being seated in the molecular agitation caused by temperature. The structural effect will depend on the maximum exposure temperature, on the assumption that cooling down to the loading temperature does not reverse any structural changes caused by heating or cause structural changes of its own.

The above assumption regarding cooling will be true only if differential thermal strains within the specimen are minimised by a slow rate of cooling and if rehydration is not allowed to take place. Where such conditions have been maintained, both strength and modulus of elasticity tests confirm that the structural effect of temperature is essentially dependent on the maximum exposure temperature. In order to isolate the thermal effect of temperature, specimens having the same structure must be loaded at different temperatures. This can only be done by heating a series of specimens to some common upper preheat temperature and loading them at various temperatures less than or equal to the preheat temperature, after slow cooling. On the other hand, in order to isolate the structural effect of temperature, specimens with different structures must be loaded at the same temperature. This can be achieved by heating a series of specimens to varying preheat temperatures and loading them at a common temperature less than or equal to the maximum preheat temperature (Dias et al., 1990).

At present, prescriptive approaches are generally employed for the fire resistance of reinforced concrete members that are based on either empirical calculation methods or standard fire resistance tests. These approaches do not provide rational and realistic fire safety assessments and have major drawbacks. New codes are moving toward performance-based design, and temperaturedependent calculations are expected to be required to satisfy certain performance criteria. There is an increased focus on the use of numerical methods for evaluating the fire performance of structural members, which depends on the properties of the constituent materials. Knowledge of the high-temperature properties of concrete is critical for fire resistance assessment under performance-based codes (Kodur et al., 2008).

The parameters that control concrete behaviour are compressive strength, tensile strength, peak strain, modulus of elasticity, creep strain, thermal conductivity and thermal strain, which are nonlinear functions of temperature. Also, types of aggregate of concrete influence the behaviour of concrete exposed to fire (Diederichs et al., 1987). Many compressive and tensile constitutive models for concrete at normal temperatures have been proposed. The constitutive laws of concrete materials under fire conditions are complicated and knowledge of current thermal properties is based on limited material properties. There are either limited test data for some elevated-temperature properties or considerable differences and inconsistencies in the elevated-temperature test data for other properties of concrete (Naus, 2006; Phan and Carino, 1998, 2003). These differences and inconsistencies are due mainly to differences in test methods, limit conditions and the environmental parameters of the tests (Flynn, 1999). Although computational methods and techniques for estimating the fire performance of the structural members of buildings have been proposed, research studies that provide inputting data such as constitutive laws of concrete materials for these computational methods have not kept pace (Kodur and Harmathy, 2002). Much of the information in ACI 216R-89 (ACI, 1989) is based on results from experimental tests undertaken during the 1950 s and 1960 s that contain no comprehensive constitutive relationships (Kodur et al., 2008).

\section{Research significance}

In this study, constitutive relationships are proposed for prestressed normal-strength concrete (NSC) and high-strength concrete (HSC) at elevated temperatures; these relationships are compared with others available and verified with previous experimental data. Regression analyses are conducted on existing experimental data to propose residual compression strength, initial modulus of elasticity, peak strain, thermal strain and transient creep strain. First, the relationships proposed for residual compression strength, initial modulus of elasticity, peak strain, thermal strain and creep strain are verified with experimental data. Then, compressive stress-strain relationships for NSC and HSC at elevated temperatures are proposed and verified with experimental data.

\section{Compressive strength of prestressed NSC and HSC at elevated temperatures}

Several models have been proposed to estimate unloaded concrete compressive strength at high temperatures. The model for the prestressed compressive strength of concrete at high temperatures is the Hertz (2005) model. Hertz (2005) proposed a model 
(Equation 1) that recognises the variation of $f_{\mathrm{cT}}^{\prime}$ with the type of aggregate

1.

$$
f^{\prime}{ }_{\mathrm{cT}}=f^{\prime} \mathrm{c}\left\{1 /\left[1+\frac{T}{T_{1}}+\left(\frac{T}{T_{2}}\right)^{2}+\left(\frac{T}{T_{8}}\right)^{8}+\left(\frac{T}{T_{64}}\right)^{64}\right]\right\}
$$

for siliceous aggregate, $T_{1}=15000, T_{2}=800, T_{8}=570$, $T_{64}=100000$

for lightweight aggregate, $T_{1}=100000, T_{2}=1100, T_{8}=800$, $T_{64}=940$

for other aggregates, $T_{1}=100000, T_{2}=1080, T_{8}=690$, $T_{64}=1000$

In this study, the relationships proposed for the prestressed compressive strength of normal, high-strength (siliceous aggregate), carbonate and lightweight aggregate prestressed concrete at elevated temperatures are based on regression analyses of existing experimental data (Gross, 1975; Schneider, 1988; Shi et al., 2002); the results are expressed in Equations 2-5. The main aim of regression analyses is to consider the changeable experimental compressive strength of concrete behaviours at different elevated temperatures and to develop rational and simple relationships that fit the experimental data well.

For NSC (siliceous aggregate) $\left(T\right.$ in $\left.{ }^{\circ} \mathrm{C}\right)$

$$
f_{\mathrm{cT}}^{\prime}=f_{\mathrm{c}}^{\prime}
$$

2. $\left\{\begin{array}{ll}1.0 & 20 \leqslant T \leqslant 200 \\ 1.06+0.00025 T & \\ -2.235 \times 10^{-6} T^{2}+8 \times 10^{-10} T^{3} & 200<T \leqslant 800 \\ 0.44-0.0004 T & 900 \leqslant T \leqslant 1000 \\ 0 & T>1000\end{array}\right\}$

For HSC (siliceous aggregate) $\left(T\right.$ in $\left.{ }^{\circ} \mathrm{C}\right)$

$$
f_{\mathrm{cT}}=f_{\mathrm{c}}^{\prime}
$$

3. $\left\{\begin{array}{ll}1 \cdot 0 & 20 \leqslant T \leqslant 100 \\ 0.83+0 \cdot 0019 T & \\ -5 \cdot 2 \times 10^{-6} T^{2}+3 \times 10^{-9} T^{3} & 100<T \leqslant 800 \\ 0 & 800<T\end{array}\right\}$

For carbonate aggregate concrete $\left(T\right.$ in $\left.{ }^{\circ} \mathrm{C}\right)$

$$
f_{\mathrm{cT}}=f_{\mathrm{c}}^{\prime}
$$

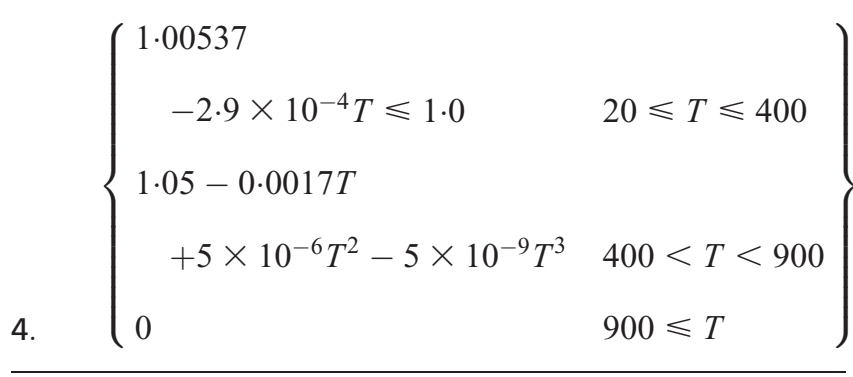

For lightweight aggregate concrete $\left(T\right.$ in $\left.{ }^{\circ} \mathrm{C}\right)$

$$
\begin{aligned}
& f_{\mathrm{cT}}=f_{\mathrm{c}}^{\prime}
\end{aligned}
$$

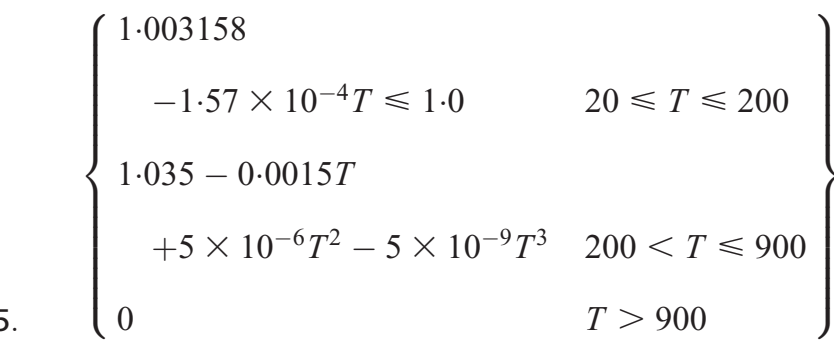

The proposed relationships at elevated temperatures are compared separately with experimental data and the Hertz (2005) model in Figures 1 and 2. Figure 1(a) compares the Hertz (2005) model and the proposed relationship for prestressed NSC at different temperatures against the experimental results of Abrams (1971) and Phan and Carino (1998). NSC typically loses $10-20 \%$ of its original compressive strength when heated to $300^{\circ} \mathrm{C}$, and $60-$ $75 \%$ at $800^{\circ} \mathrm{C}$. Figure 1 (b) shows the proposed relationship for prestressed HSC at different temperatures compared with the experimental results of Castillo and Durani (1990), Khoury et al. (2002) and Phan and Carino (1998) - the relationship fits the experimental results well. Higher rates of original strength loss, as much as $40 \%$, were observed for HSC at temperatures up to $800^{\circ} \mathrm{C}$. Figure 2 shows a comparison of the Hertz (2005) model and the proposed relationships against the experimental results of Abrams (1971) for (a) carbonate aggregate and (b) lightweight aggregate prestressed concrete. The proposed relationships fit the experimental results well.

\section{Prestressed elastic modulus of concrete at elevated temperatures}

The elastic modulus of concrete could be affected primarily by the same factors influencing its compressive strength (Malhotra, 1982). The most important available models for the elastic modulus of prestressed concrete at high temperatures are summarised in Table 1. The following relationship $\left(T\right.$ in $\left.{ }^{\circ} \mathrm{C}\right)$ is proposed using regression analyses conducted on experimental data (Gross, 1975; Schneider, 1988) 


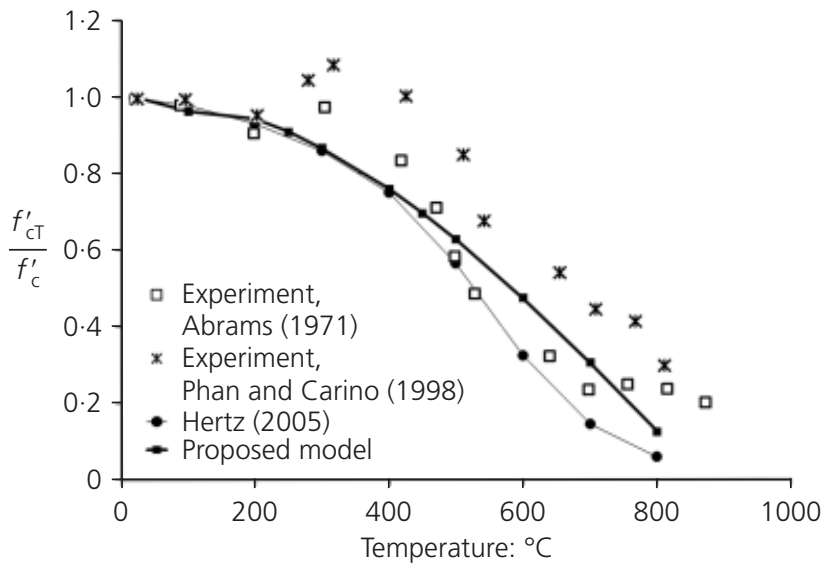

(a)

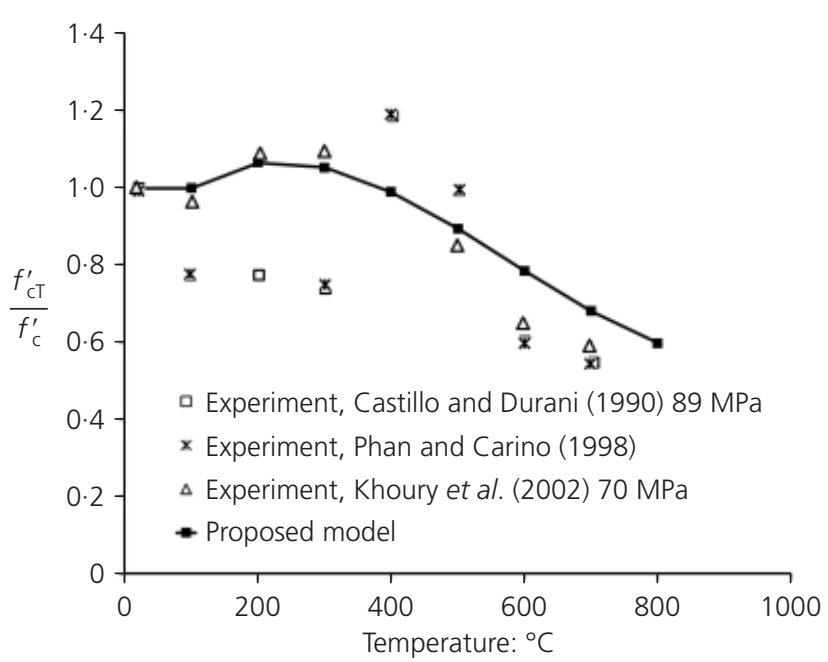

(b)

Figure 1. Comparison of compressive strength models and experimental data for prestressed (a) NSC and (b) HSC at elevated temperatures

$$
\text { 6. } E_{\mathrm{crT}}=E_{\mathrm{c}}\left\{\begin{array}{ll}
1.0 & T=20 \\
1.03-0.00025 T & \\
-9 \times 10^{-7} T^{2} & 100 \leqslant T \leqslant 800 \\
0 & T>800
\end{array}\right\}
$$

Figure 3 provides a comparison of the models given in Table 1, the proposed relationship and the experimental results of Anderberg and Thelandersson (1976) and Khoury et al. (2002). The elastic modulus of concrete typically loses $10-20 \%$ of its original elastic modulus when heated to $300^{\circ} \mathrm{C}$ and $70-80 \%$ at $800^{\circ} \mathrm{C}$. The proposed relationship fits most of the experimental results well.

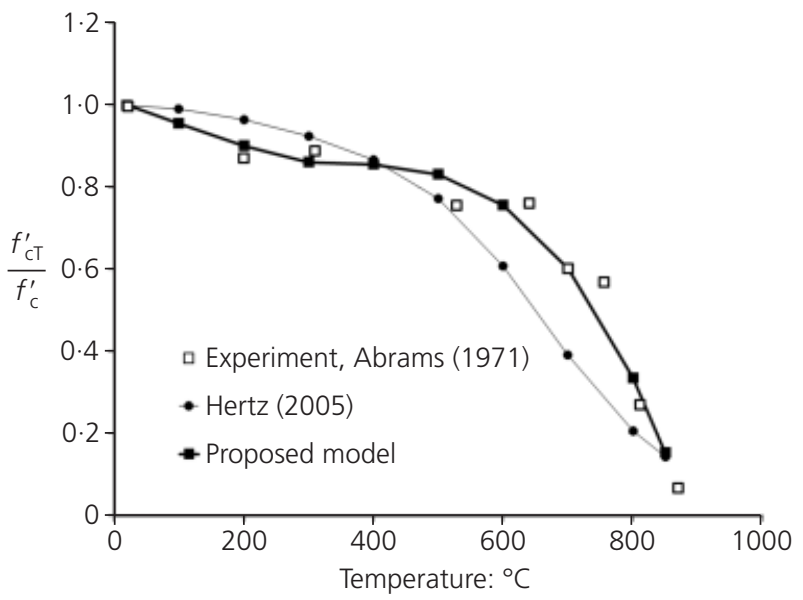

(a)

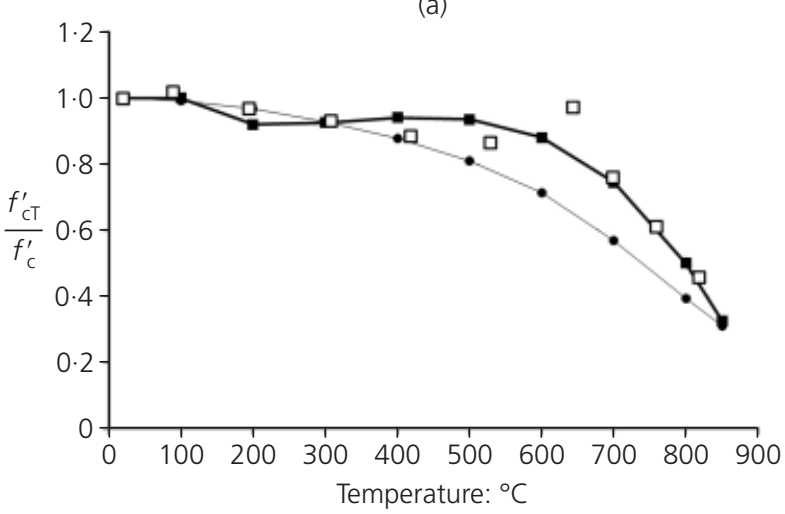

(b)

Figure 2. Comparison of compressive strength models and experimental data for (a) carbonate aggregate and

(b) lightweight aggregate prestressed concrete at elevated temperatures

\section{Strain at the peak stress of prestressed concrete at elevated temperatures}

The most important models for the peak strain of prestressed concrete at high temperatures are those proposed by Khennane and Baker (1993) and Terro (1998). Khennane and Baker (1993) studied the experimental results provided by Anderberg and Thelandersson (1976) and proposed the following equation for the peak strain of concrete having an initial compressive stress during heating process

$$
\varepsilon_{\max }=0.00000167 T+0.002666 \geqslant 0.003
$$

7.

$$
\text { if } T \leqslant 800^{\circ} \mathrm{C}
$$

Terro (1998) proposed the following equation for the peak strain of concrete, which accounts for the initial compressive stress level. 
Anderberg and Thelandersson (1976)

$$
E_{\mathrm{CrT}}=\frac{2 f_{\mathrm{CT}}^{\prime}}{\varepsilon_{\mathrm{CT}}^{\prime}}
$$

Schneider (1986)

Normal weight

$$
\begin{aligned}
& E_{\text {crT }}=(-0.001552 T+1.03104) g E_{\mathrm{c}} \quad 20 \leqslant T \leqslant 600 \\
& E_{\text {crT }}=(-0.00025 T+0.25) g E_{\mathrm{c}} \quad 600 \leqslant T \leqslant 1000
\end{aligned}
$$

Schneider (1986)

Lightweight

$$
\begin{aligned}
& E_{\mathrm{CrT}}=(-0.00102 T+1.0204) g E_{\mathrm{c}} \quad 20 \leqslant T \leqslant 1000 \\
& g=1+\frac{f_{\mathrm{ci}}}{f_{\mathrm{c}}^{\prime}} \frac{T-20}{100} \quad \frac{f_{\mathrm{ci}}}{f_{\mathrm{c}}^{\prime}} \leqslant 3.0
\end{aligned}
$$

Khennane and Baker (1993)

Preloaded

$$
\begin{aligned}
& E_{\mathrm{crT}}=(-0.000634 T+1.012673) E_{\mathrm{c}} \quad 20 \leqslant T \leqslant 525 \\
& E_{\mathrm{crT}}=(-0.002036 T+1.749091) E_{\mathrm{c}} \quad 525 \leqslant T \leqslant 800
\end{aligned}
$$

Table 1. Prestressed elastic modulus models of concrete at elevated temperatures $\left(T\right.$ in $\left.{ }^{\circ} \mathrm{C}\right)$

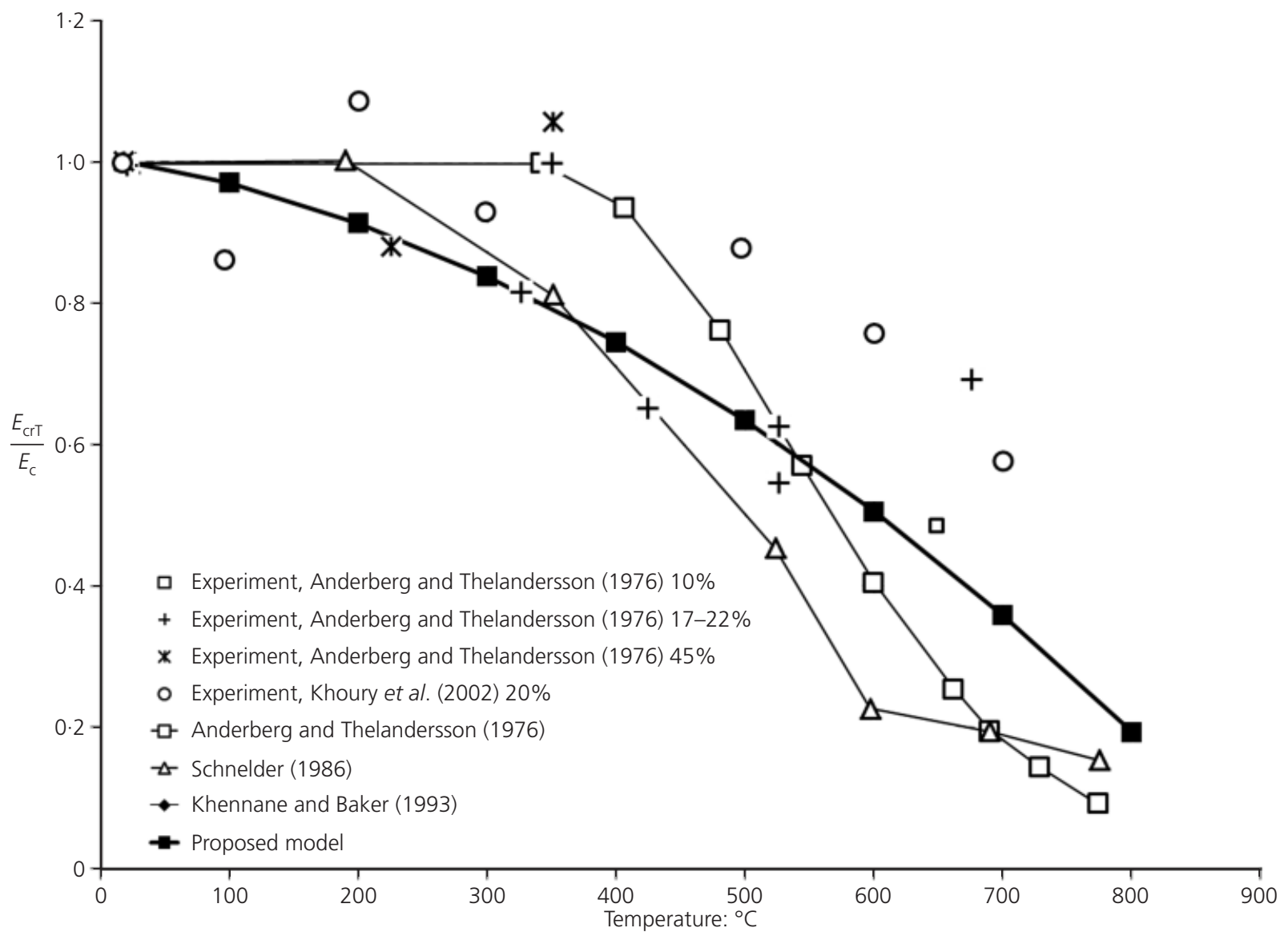

Figure 3. Comparison of elastic modulus models of prestressed concrete at elevated temperatures with experimental data 


$$
\varepsilon_{\max }=\left(50 \lambda_{\mathrm{L}}^{2}-15 \lambda_{\mathrm{L}}+1\right) \varepsilon_{\mathrm{c} 1}^{\prime}+20\left(\lambda_{\mathrm{L}}-5 \lambda_{\mathrm{L}}^{2}\right) \varepsilon_{\mathrm{c} 2}^{\prime}
$$

8.

$$
+5\left(10 \lambda_{\mathrm{L}}^{2}-\lambda_{\mathrm{L}}\right) \varepsilon_{\mathrm{c} 3}^{\prime}
$$

where

$$
\begin{aligned}
\varepsilon_{\mathrm{c} 1}^{\prime}= & 2.05 \times 10^{-3}+3.08 \times 10^{-6} T \\
& +6.17 \times 10^{-9} T^{2}+6.58 \times 10^{-12} T^{3} \\
\varepsilon_{\mathrm{c} 2}^{\prime}= & 2.03 \times 10^{-3}+1.27 \times 10^{-6} T \\
& +2.17 \times 10^{-9} T^{2}+1.64 \times 10^{-12} T^{3} \\
\varepsilon_{\mathrm{c} 3}^{\prime}= & 0.002
\end{aligned}
$$

Using regression analyses conducted on experimental data (Xiao and Konig, 2004), Equation 9 gives a new proposal to evaluate the peak strain of prestressed concrete at elevated temperatures.

9. $\varepsilon_{\max }=0.0028+2 \times 10^{-6} T \quad 20 \leqslant T \leqslant 800$

Figure 4 provides a comparison of the proposed relationship, the models of Khennane and Baker (1993) and Terro (1998) and the experimental results of Anderberg and Thelandersson (1976). Compared with the peak strain under high temperature, the peak strain of concrete after a high temperature is slightly larger. Compared with the other models, the proposed relationship shows good accuracy with the experimental results.

\section{Thermal strain of unloaded and prestressed concrete}

Free thermal expansion is affected predominantly by aggregate type; expansion is not linear with respect to temperature. The presence of free moisture will affect the results below $150^{\circ} \mathrm{C}$ since water being driven off may cause net shrinkage. Traditionally, it is expressed as a linear function of temperature by

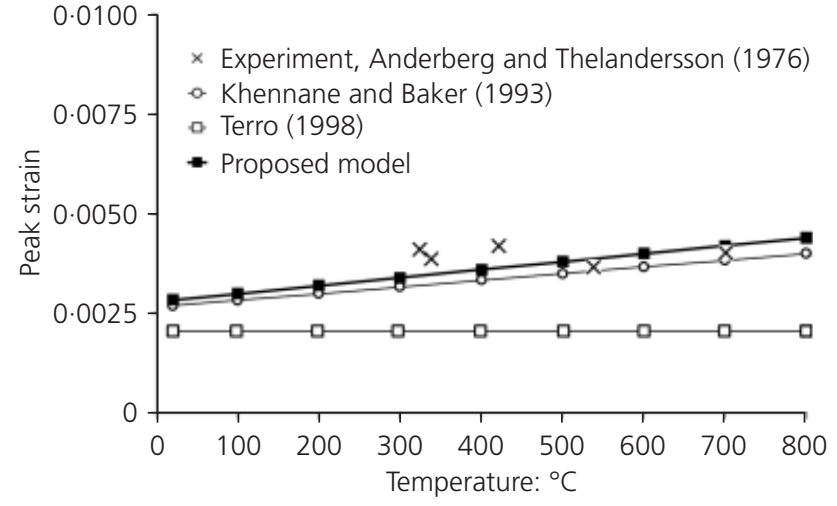

Figure 4. Comparison of peak strain models of prestressed concrete at elevated temperatures with experimental data

employing a thermal expansion coefficient $\alpha$ ( $\mathrm{Li}$ and Purkiss, 2005).

10. $\varepsilon_{\mathrm{th}}=\alpha(T-20)$

For concrete with siliceous or carbonate aggregates, $\alpha$ can be taken as equal to $18 \times 10^{-6}$ or $12 \times 10^{-6}$ per $^{\circ} \mathrm{C}$ (Purkiss, 1996). The most important available models for the thermal strain of unloaded concrete at high temperatures are summarised in Table 2 .

New relationships are proposed here (Equations $11-14 ; T$ in ${ }^{\circ} \mathrm{C}$ ) to evaluate the thermal strain of unloaded siliceous, carbonate and lightweight aggregate concretes at elevated temperatures using regression analyses conducted on experimental data (Gross, 1975; Khoury et al., 1985; Schneider, 1988; Shi et al., 2002; Sullivan et al., 1983; Thienel and Rostasy, 1996).

For siliceous aggregate concrete

$$
\varepsilon_{\text {th }}=0.00045+1 \times 10^{-6} T+2 \times 10^{-8} T^{2}
$$

11. $100 \leqslant T \leqslant 800$

\begin{tabular}{lll}
\hline Reference & Aggregate & Model \\
\hline Lie (1992) & Siliceous and carbonate & $\varepsilon_{\text {th }}=\left[0.004\left(T^{2}-400\right)+6(T-20)\right] \times 10^{-6}$ \\
BSI (2004) & Siliceous & $\varepsilon_{\text {th }}=\left\{\begin{array}{ll}-1.8 \times 10^{-4}+9 \times 10^{-6} T+2.3 \times 10^{-11} T^{3} & 20 \leqslant T \leqslant 700 \\
14 \times 10^{-3} & 700 \leqslant T \leqslant 1200\end{array}\right\}$ \\
BSI (2004) & Carbonate & $\varepsilon_{\text {th }}=\left\{\begin{array}{ll}-1.2 \times 10^{-4}+6 \times 10^{-6} T+1.4 \times 10^{-11} T^{3} & 20 \leqslant T \leqslant 805 \\
12 \times 10^{-3} & 805 \leqslant T \leqslant 1200\end{array}\right\}$
\end{tabular}

Table 2. Thermal strain models (unloaded concrete) $\left(T\right.$ in $\left.{ }^{\circ} \mathrm{C}\right)$ 
For different compressive strengths (the compressive strength range is given in Table 3)

$$
\varepsilon_{\text {th }}=\alpha\left(0.00045+1 \times 10^{-6} T+2 \times 10^{-8} T^{2}\right)
$$

12. $100 \leqslant T \leqslant 800$

For carbonate aggregate concrete

$$
\varepsilon_{\text {th }}=0.0001+5 \times 10^{-7} T+2 \times 10^{-8} T^{2}
$$

13. $100 \leqslant T \leqslant 800$

For lightweight aggregate concrete

$$
\text { 14. } \varepsilon_{\text {th }}=-0.00045+8 \times 10^{-6} T \quad 100 \leqslant T \leqslant 800
$$

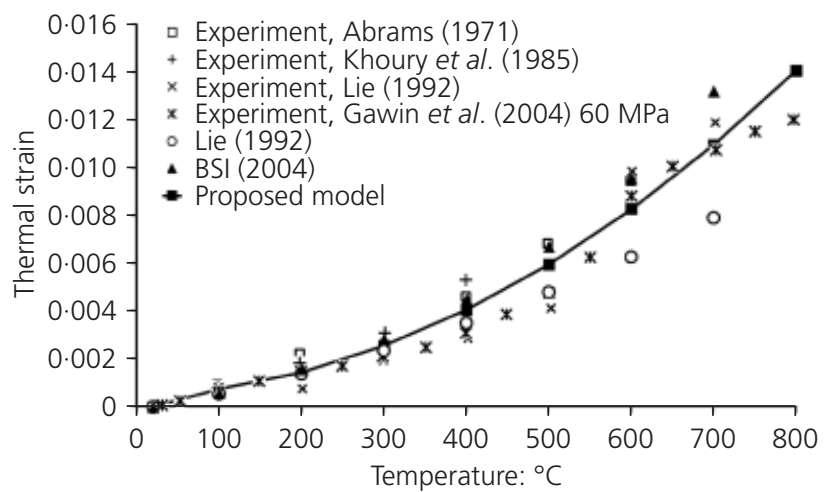

(a)

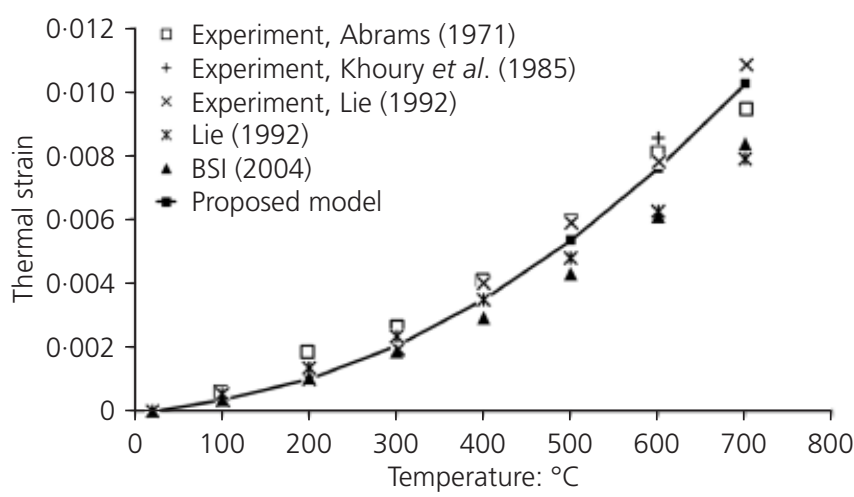

(c)

Figure 5. Comparison of thermal strain models of

(a) normal-strength unloaded siliceous aggregate,

(b) high-strength unloaded siliceous aggregate, (c) unloaded carbonate aggregate and (d) unloaded lightweight aggregate concrete at elevated temperatures with experimental data

\begin{tabular}{lllllll}
\hline & \multicolumn{6}{c}{$\alpha$} \\
\cline { 2 - 6 } & 1.00 & 0.85 & 0.75 & 0.65 & 0.50 \\
\hline Compressive strength: MPa & $20-60$ & 70 & 80 & 90 & 100
\end{tabular}

Table 3. Compressive strength range

Thermal strain is a non-linear function of temperature, even at relatively low temperatures. The main factor affecting thermal strain is the type of aggregate; the coarse aggregate fraction plays a dominant role. Figure 5(a) provides a comparison between models of Lie (1992) and BS EN 1992-1-2 (BSI, 2004) and the proposed relationship for the thermal strain of normal-strength unloaded siliceous aggregate concrete against the experimental results of Abrams (1971), Khoury et al. (1985), Lie (1992) and Gawin et al. (2004). Figure 5(b) shows a comparison between the Lie (1992) and

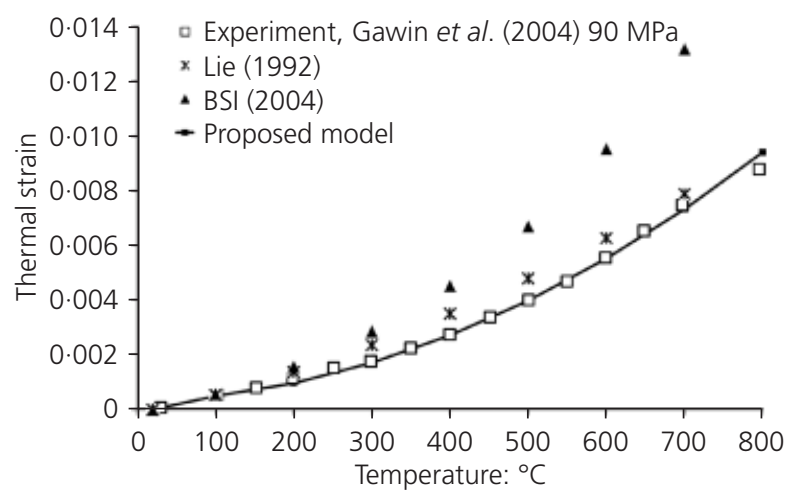

(b)

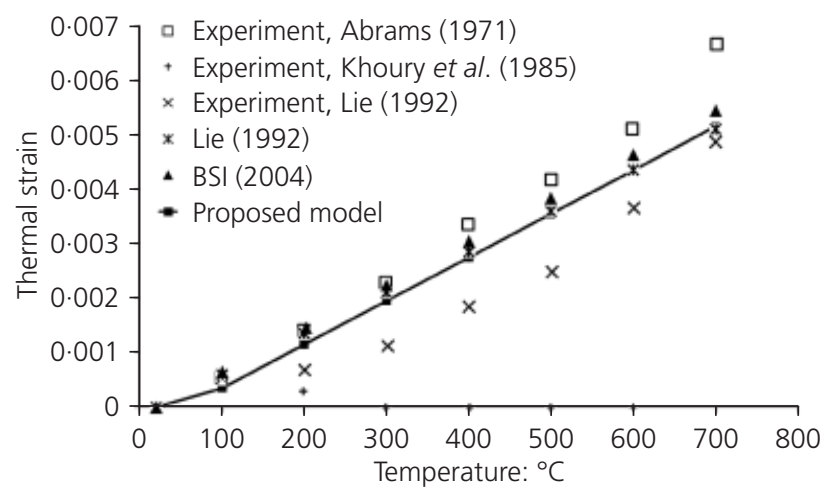

(d) 
BS EN 1992-1-2 (BSI, 2004) models and the proposed relationship for the thermal strain of unloaded siliceous aggregate concrete against the experimental results of Gawin et al. (2004). Figures 5(c) and 5(d) provide a comparison between the Lie (1992) and BS EN 1992-1-2 (BSI, 2004) models and the proposed relationship for thermal strain of unloaded carbonate and lightweight aggregate concretes separately against the experimental results of Abrams (1971), Khoury et al. (1985) and Lie (1992). The proposed relationships show good accuracy with the experimental results in comparison with the other models.

In this study, relationships (Equations 15-18) are proposed as a function of preloading percentages of the concrete compressive strength at room temperature $\left(f_{\mathrm{c}}^{\prime}\right)$ to evaluate the thermal strain of prestressed concrete at elevated temperatures using regression analyses conducted on experimental data (Gross, 1975; Khoury et al., 1985; Schneider, 1988; Shi et al., 2002; Sullivan et al., 1983; Thienel and Rostasy, 1996).

For prestressing of $10-15 \%$ of $f_{\mathrm{c}}^{\prime}$

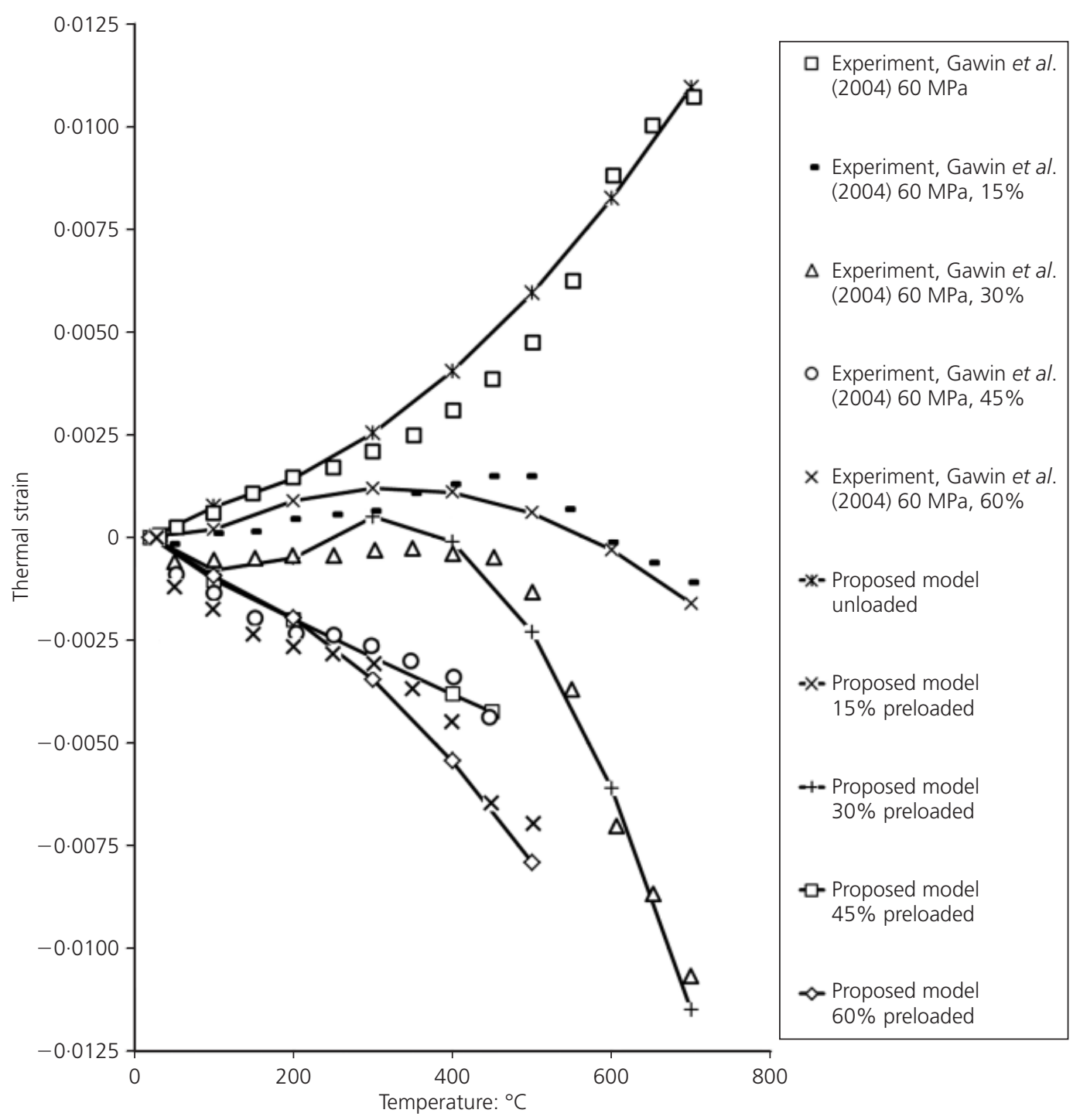

Figure 6. Comparison of thermal strain models of prestressed concrete at elevated temperatures with experimental data 
For prestressing of $15-30 \%$ of $f_{\mathrm{c}}^{\prime}$

$\varepsilon_{\mathrm{th}}=\left\{\begin{array}{cc}0.0002-10^{-5} T & 20 \leqslant T<200 \\ -0.0073+5 \times 10^{-5} T & \\ -8 \times 10^{-8} T^{2} & 200 \leqslant T \leqslant 800\end{array}\right\}$

For prestressing of $30-45 \%$ of $f_{\mathrm{c}}^{\prime}$

17. $\quad \varepsilon_{\mathrm{th}}=\left\{\begin{array}{ll}0 & T=20 \\ -0.00005-1 \times 10^{-5} T & \\ -1.5 \times 10^{-9} T^{2} & 100 \leqslant T \leqslant 800\end{array}\right\}$
For prestressing of $45-60 \%$ of $f_{\mathrm{c}}^{\prime}$
18.
$\varepsilon_{\mathrm{th}}=\left\{\begin{array}{l}0 \\ -0.0004-3 \times 10^{-6} T \\ \quad-2.4 \times 10^{-8} T^{2}\end{array}\right.$
$T=20$
$100 \leqslant T \leqslant 800$

Figure 6 compares the proposed relationships against the experimental results of Gawin et al. (2004) for unloading and preloading of $15,30,45$ and $60 \%$ of $f_{\mathrm{c}}^{\prime}$. The proposed relationships fit most of the experimental results very well, which indicates that the higher the preloading percentage is, the lower the thermal strain will be. This figure also indicates the trend of the thermal strain-temperature curves, which is entirely a function of the preloading percentage.

Reference Model

Anderberg and

Thelandersson (1976)

$$
\begin{aligned}
& \varepsilon_{\mathrm{tr}}=k_{\mathrm{tr}}\left(\frac{\sigma_{\mathrm{cT}}}{f_{\mathrm{c}}^{\prime}}\right) \varepsilon_{\mathrm{th}} \quad T \leqslant 550 \mathrm{C} \\
& \frac{\partial \varepsilon_{\mathrm{tr}}}{\partial T}=0.0001\left(\frac{\sigma_{\mathrm{cT}}}{f_{\mathrm{c}}^{\prime}}\right) \quad T \geqslant 550 \\
& 1.8 \leqslant k_{\mathrm{tr}} \leqslant 2.35
\end{aligned}
$$

Schneider (1986)

$$
\begin{aligned}
& \varepsilon_{\mathrm{tr}}=\frac{\phi}{g} \frac{f_{\mathrm{c}}^{\prime}}{E_{\mathrm{cr}}} \\
& \phi=g\left\{C_{1} \tanh \left(\gamma_{\mathrm{w}(T-20)}\right)+C_{2} \tanh \left[\gamma_{\mathrm{o}}\left(T-T_{\mathrm{g}}\right)\right]+C_{3}\right\}+\frac{\sigma_{\mathrm{CT}}}{f^{\prime}{ }_{\mathrm{CT}}} \frac{T-20}{100}
\end{aligned}
$$$$
\frac{\sigma_{\mathrm{CT}}}{f_{\mathrm{CT}}^{\prime}} \leqslant 3.0
$$

Diederichs (1987)

$$
\begin{aligned}
& \gamma_{\mathrm{w}}=(0.3 \mathrm{w}+2.2) \times 10^{-3} \\
& \varepsilon_{\mathrm{tr}}=\frac{\sigma_{\mathrm{cT}}}{f_{\mathrm{c}}^{\prime}}\left[3.3 \times 10^{-10}(T-20)^{3}-1.72 \times 10^{-7}(t-20)^{2}+0.0412 \times 10^{-3}(T-20)\right]
\end{aligned}
$$

Terro (1998)

$$
\varepsilon_{\mathrm{tr}}=\varepsilon_{0.3} \times\left(0.032+3.226 \frac{f_{\mathrm{ci}}}{f_{\mathrm{c}}^{\prime}}\right) \frac{V_{\mathrm{a}}}{0.65}
$$$$
\frac{f_{\mathrm{Ci}}}{f_{\mathrm{CT}}^{\prime}} \leqslant 3.0
$$

b

$$
\begin{aligned}
\varepsilon_{0.3}= & -43.87 \times 10^{-6}+2.73 \times 10^{-8} T+6.35 \times \times 10^{-8} T^{2}-2.19 \times 10^{-10} T^{3}+2.77 \times 10^{-13} T^{4} \\
\varepsilon_{0.3}= & -1625.78 \times 10^{-6}+58.03 \times 10^{-6} T-0.6364 \times 10^{-6} T^{2}+3.6112 \times 10^{-9} T^{3} \\
& -9.2796 \times 10^{-12} T^{4}+8.806 \times 10^{-15} T^{5}
\end{aligned}
$$

Nielsen et al. (2002)

$$
\varepsilon_{t r}=0.000038\left(\frac{\sigma_{c T}}{f_{c}^{\prime}}\right) T
$$

\footnotetext{
a $W$ is moisture content; $C_{1}, C_{2}, C_{3}, \gamma_{0}$ and $T_{\mathrm{g}}$ are constants with values of 2.60, 1.40,1.40,0.0075 and 700 for concrete with siliceous aggregates; $2 \cdot 60,2 \cdot 40,2 \cdot 40,0.0075$ and 650 for concrete with carbonate aggregate; $2 \cdot 60,3.00,3.00,0.0075$ and 600 for concrete with lightweight aggregate

${ }^{b}$ concrete with carbonate and lightweight aggregates

c concrete with siliceous aggregates
} 


\section{Creep strain at elevated temperatures}

It has been observed that prestressed concrete elements experience a characteristic marked increase in strains during the initial heating (Khoury et al., 1986; Kordina et al., 1986). This increase significantly exceeded the expected creep strains and has been referred to as transient creep strain (Lie, 1992; Purkiss, 1996; Thelandersson, 1987). The most important models for the creep strain of concrete at high temperatures are summarised in Table 4. Equations 19-21 are proposed to evaluate the creep strain of prestressed concrete at elevated temperatures using regression analyses conducted on experimental data (Gross, 1975; Khoury et al., 1986; Schneider, 1988; Thienel and Rostasy, 1996).

For prestressing of $10-20 \%$ of $f_{\mathrm{c}}^{\prime}$

$$
\varepsilon_{\text {tr }}=0.0006-3.8 \times 10^{-6} T+2.25 \times 10^{-8} T^{2}
$$

19. $100 \leqslant T \leqslant 600$

For prestressing of $20-40 \%$ of $f_{\mathrm{c}}^{\prime}$

$$
\varepsilon_{\mathrm{tr}}=0.00095-6 \times 10^{-6} T+3 \times 10^{-8} T^{2}
$$

20. $100 \leqslant T \leqslant 600$

For prestressing of $40-60 \%$ of $f_{\mathrm{c}}^{\prime}$

$$
\varepsilon_{\text {tr }}=-8 \times 10^{-5}+4.1 \times 10^{-6} T+3 \times 10^{-8} T^{2}
$$

21. $100 \leqslant T \leqslant 600$

Transient tests for measuring the total deformation or restraint of concrete have, in principle, the strongest relation to building fires and are supposed to give the most realistic data with direct relevance to fire. The tests yielded strain-temperature relationships for given heating rates. Figure 7 shows that the proposed relationships fit most of the experimental results well and also agree with the model of Nielsen et al. (2002), which is linear and rational with the experimental results at temperatures of less than $500^{\circ} \mathrm{C}$. The test results support the hypothesis that the high-temperature creep potential is a unique property of concrete that may be activated in a comparatively short period of time or be consumed within a long period of loading depending on moisture transfer and the temperature state of the concrete (i.e. thermodynamic equilibrium in the concrete plays an important role in this connection (Schneider, 1988)). This can be used if simplified calculations are required. Schneider's model (Schneider, 1986) provides a lower bound for the experimental results.

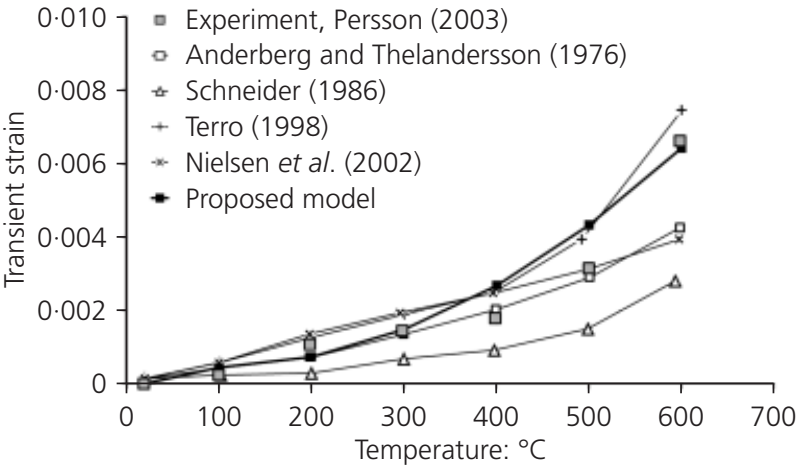

(a)

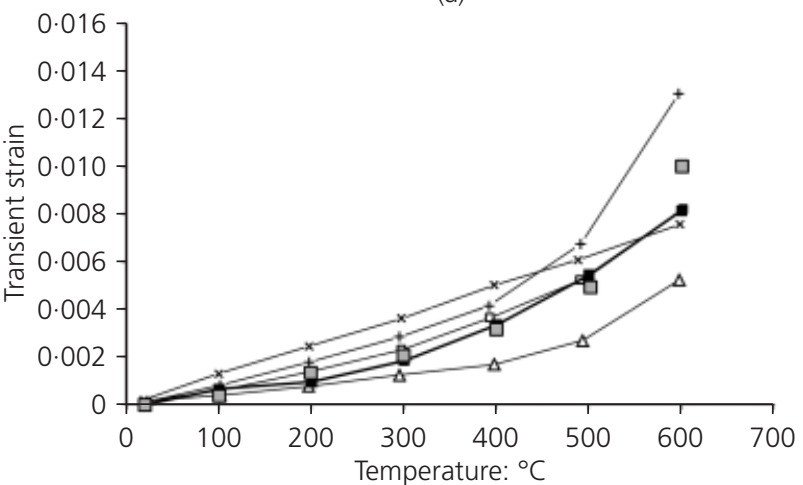

(b)

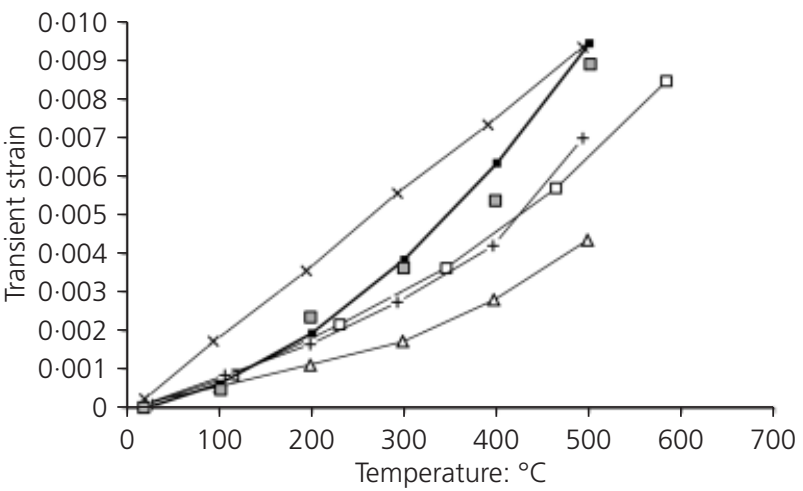

(c)

Figure 7. Relationship between transient creep strain and temperature for (a) $16.7 \%$, (b) 33\% and (c) 50\% preloading stress level

\section{Compressive stress-strain relationship at elevated temperatures}

The most important available compressive stress-strain relationships for concrete are summarised in research conducted recently by Aslani (2010), Aslani and Jowkarmeimandi (2012) and Aslani and Nejadi (2012). In these works, a compressive stress-strain relationship for NSC and HSC at elevated temperatures, based on the model of Carreira and Chu (1985) with several modifications, was developed by using the proposed residual compression strength, initial modulus of elasticity, peak strain, thermal strain and transient creep strain (Equations 22-24). 
22. $\frac{\sigma_{\mathrm{cT}}}{f_{\mathrm{cT}}^{\prime}}=\frac{\eta_{\mathrm{mT}}\left(\varepsilon_{\mathrm{cT}} / \varepsilon_{\max }\right)}{\eta_{\mathrm{mT}}-1+\left(\varepsilon_{\mathrm{cT}} / \varepsilon_{\mathrm{max}}\right)^{\eta_{\mathrm{mT}}}}$

$$
\begin{gathered}
\eta_{\mathrm{mT}}=\eta_{\mathrm{mT}, \mathrm{a}}(\text { fitted })=\left[1 \cdot 02-1 \cdot 17\left(E_{\mathrm{p}} / E_{\mathrm{c}}\right)\right]^{-0 \cdot 74} \\
\text { if } \varepsilon_{\mathrm{cT}} \leqslant \varepsilon_{\mathrm{max}} \\
\eta_{\mathrm{mT}}=\eta_{\mathrm{mT}, \mathrm{d}}(\text { fitted })=\eta_{\mathrm{mT}, \mathrm{a}}(\text { fitted })+(\gamma+\lambda t)
\end{gathered}
$$

23.

if $\varepsilon_{\mathrm{cT}} \geqslant \varepsilon_{\mathrm{max}}$

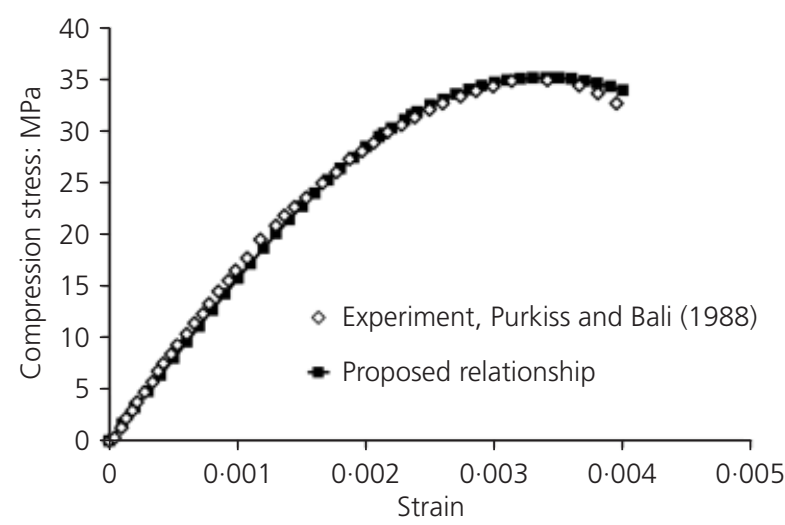

(a)

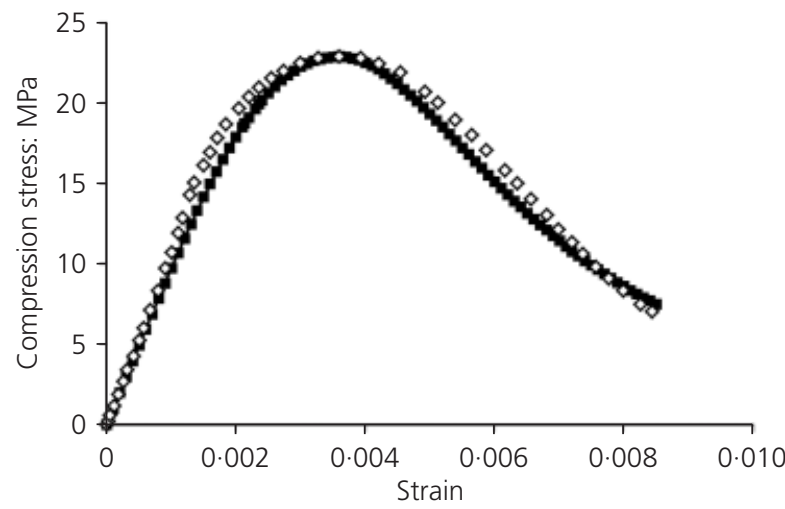

(b)

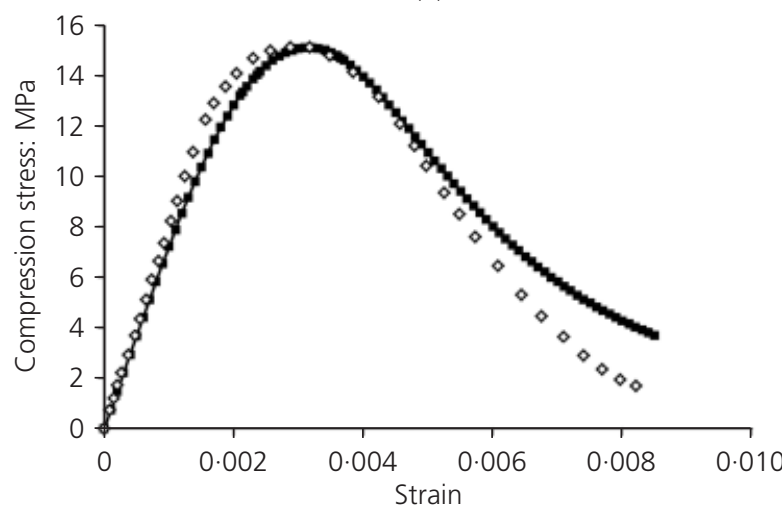

(c)

Figure 8. Comparison of the proposed relationship for $20 \%$ prestressed NSC with experimental results of Purkiss and Bali (1988) at (a) $200^{\circ} \mathrm{C}$, (b) $550^{\circ} \mathrm{C}$ and (c) $700^{\circ} \mathrm{C}$

$$
\gamma=2.7 \times\left(12.4-1.66 \times 10^{-2} f_{\mathrm{cT}}^{\prime}\right)^{-0.46}
$$

24. $\lambda=0.83 \exp \left(-911 / f_{\mathrm{cT}}^{\prime}\right)$

Figure 8 provides a comparison of the proposed relationship for $20 \%$ prestressed NSC with the experimental results of Purkiss and Bali $(1988)$ at $200^{\circ} \mathrm{C}, 550^{\circ} \mathrm{C}$ and $700^{\circ} \mathrm{C}$. The proposed model shows good agreement with the experimental results. Figure 9 compares the proposed relationship for $60 \%$ prestressed NSC
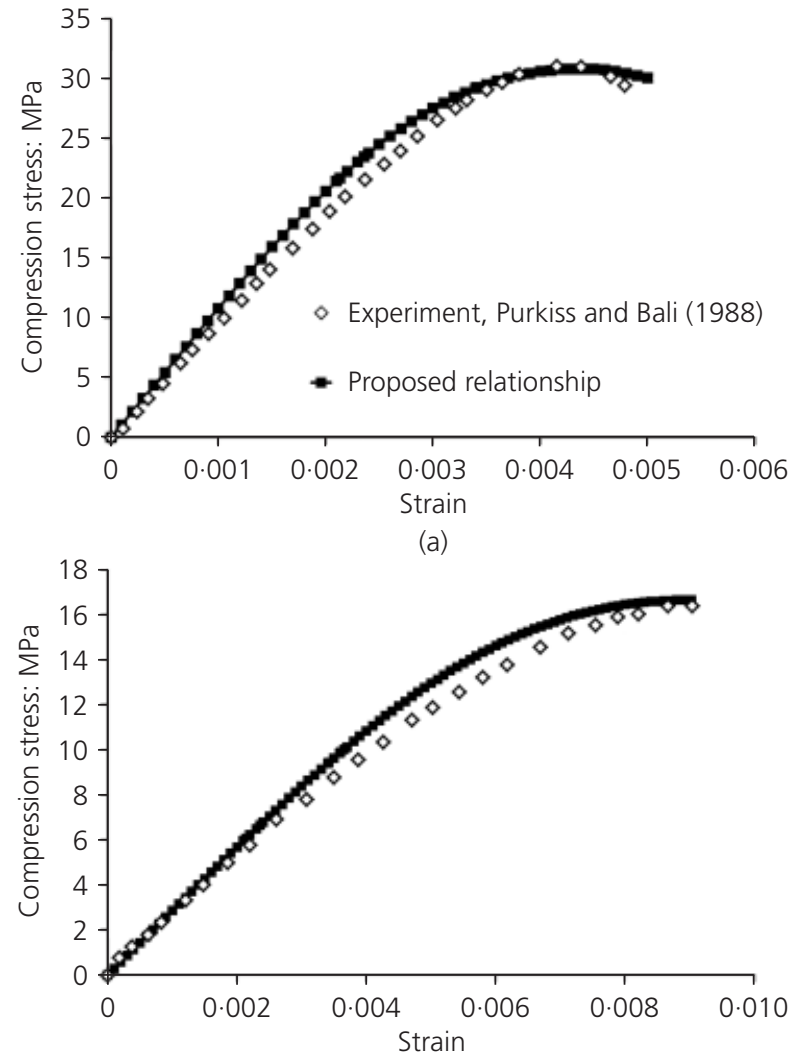

(b)

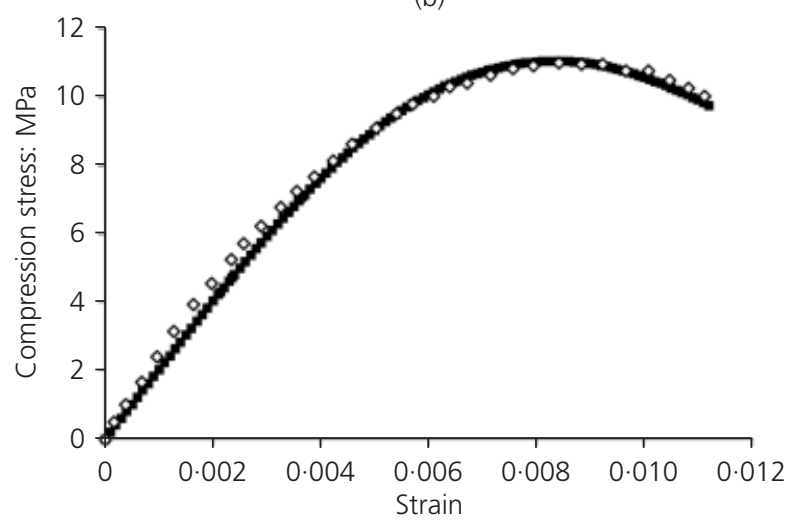

(c)

Figure 9. Comparison of the proposed relationship for $60 \%$ prestressed NSC with experimental results of Purkiss and Bali (1988) at (a) $200^{\circ} \mathrm{C}$, (b) $575^{\circ} \mathrm{C}$ and (c) $700^{\circ} \mathrm{C}$ 
with the experimental results of Purkiss and Bali (1988) at $200^{\circ} \mathrm{C}, 575^{\circ} \mathrm{C}$ and $700^{\circ} \mathrm{C}$. The proposed relationship shows good agreement with the experimental results at elevated temperatures. Figure 10 provides a comparison of the proposed relationship for $20 \%$ prestressed HSC with the experimental results of Khoury et al. (1986) at $20^{\circ} \mathrm{C}, 100^{\circ} \mathrm{C}, 300^{\circ} \mathrm{C}, 500^{\circ} \mathrm{C}$ and $600^{\circ} \mathrm{C}$. The

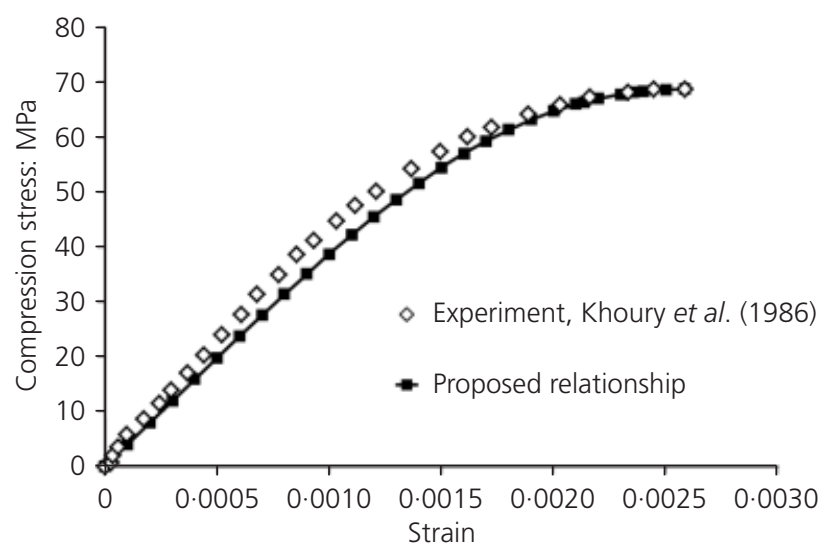

(a)

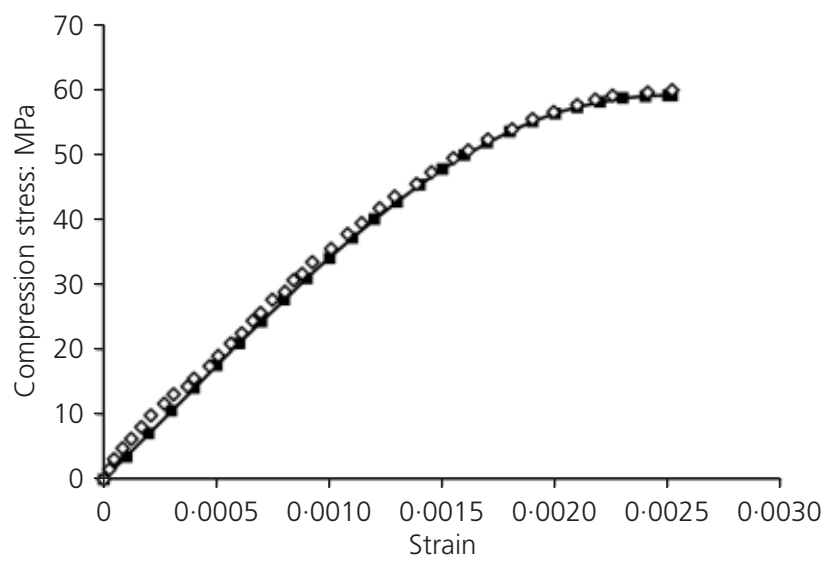

(c) proposed relationship is rational and fits the experimental results well.

\section{Conclusions}

Constitutive relationships for prestressed NSC and HSC subjected to fire have been proposed. The relationships are intended to

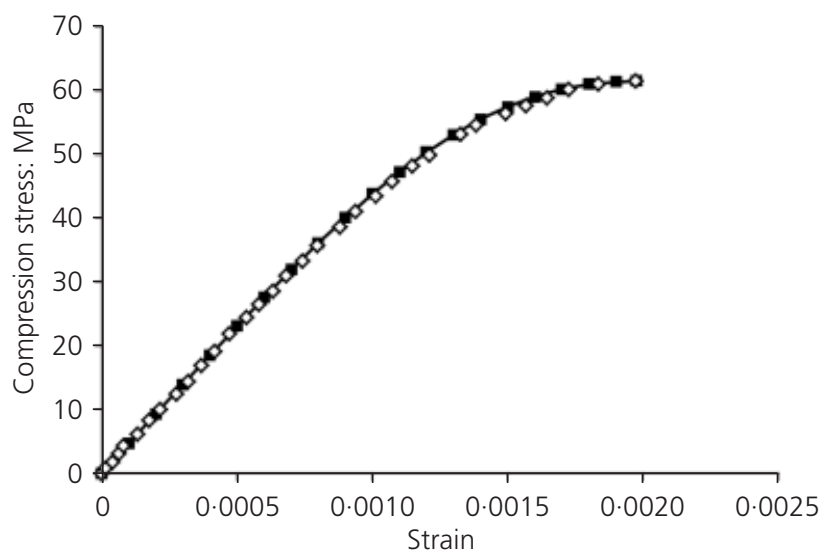

(b)

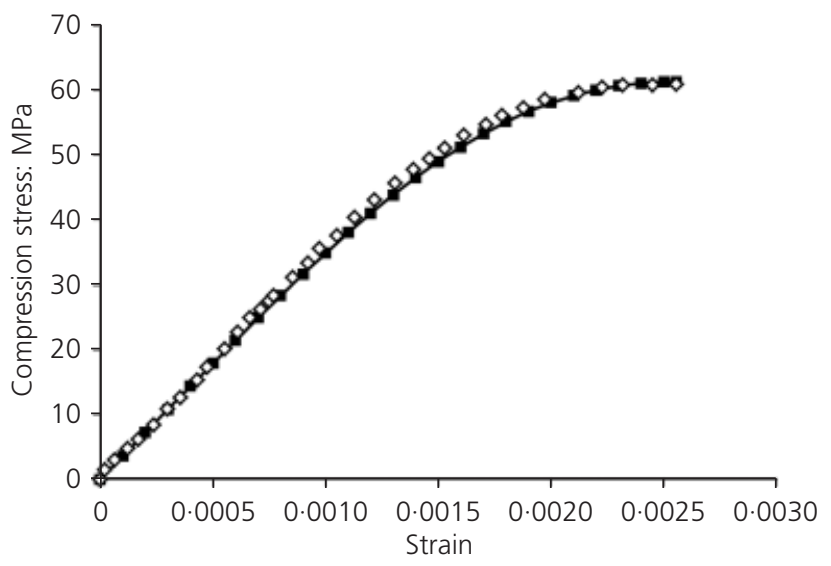

(d)

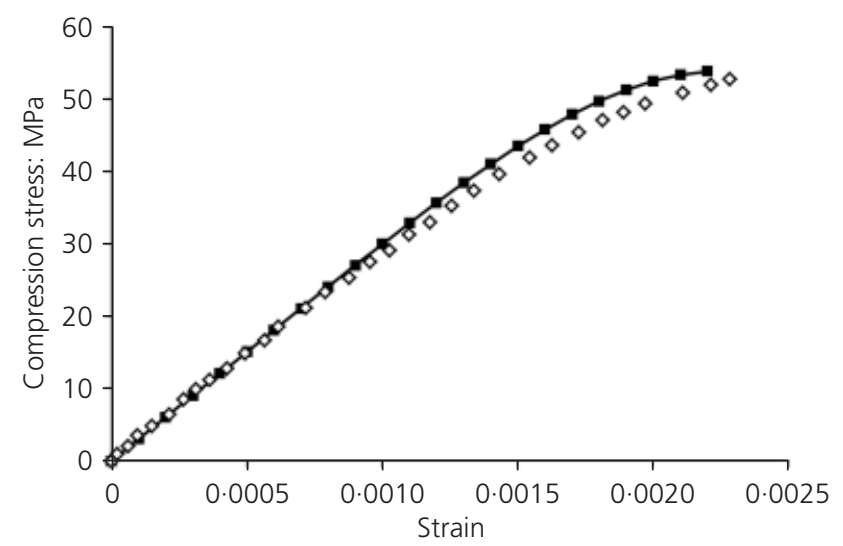

(e)

Figure 10. Comparison of the proposed relationship for $20 \%$ prestressed HSC with experimental results of Khoury et al. (1986) at (a) $20^{\circ} \mathrm{C}$, (b) $100^{\circ} \mathrm{C}$, (c) $300^{\circ} \mathrm{C}$, (d) $500^{\circ} \mathrm{C}$ and (e) $600^{\circ} \mathrm{C}$ 
provide efficient modelling for specific fire-performance criteria of the behaviour of concrete structures exposed to high temperatures. The major conclusions derived from the present work are as follows.

- The proposed relationships for compressive strength at elevated temperatures for prestressed NSC and HSC (siliceous), carbonate and lightweight aggregate concretes are in good agreement with the experimental results.

- The proposed relationship for the elastic modulus of prestressed concrete at elevated temperatures is rational and compatible with the experimental results.

- The proposed relationship for the peak strain of prestressed concrete at high temperatures shows good agreement with the experimental results, but further experimental tests are needed for further verification and improvement of the proposed model.

- The free thermal strain relationships proposed for unloaded and prestressed concrete at high temperatures are verified by the experimental results.

- The creep strain relationships for prestressed concrete at high temperatures show good agreement with the experimental results.

- The compressive stress-strain relationship for concrete was proposed based on well-established relationships for concrete at elevated temperatures. It shows good conformity with experimental test results on NSC and HSC at different high temperatures.

- Additional tests at different temperatures are needed to study further the compressive strength, concrete peak strain and initial modulus of elasticity of prestressed concrete. Tests are also required to assess the tension properties of prestressed concrete at elevated temperatures.

\section{REFERENCES}

Abrams MS (1971) Compressive strength of concrete at temperatures to $1600^{\circ} \mathrm{F}$. In Temperature and Concrete. American Concrete Institute, Detroit, MI, USA, SP-25, pp. 33-59.

ACI (American Concrete Institute) (1989) ACI 216R-89: Guide for determining the fire endurance of concrete elements. American Concrete Institute, Farmington Hills, MI, USA.

Anderberg Y and Thelandersson S (1976) Stress and Deformation Characteristics of Concrete at High Temperatures: 2 Experimental Investigation and Material Behavior Model. Lund Institute of Technology, Lund, Sweden, Bulletin 54.

Aslani F (2010) A Comparative Study of Cyclic Constitutive Models for Concrete. MSc thesis, University of Kurdistan, Sanandaj, Iran.

Aslani F and Jowkarmeimandi J (2012) Stress-strain model for concrete under cyclic loading. Magazine of Concrete Research 64(8): 673-685, http://dx.doi.org/10.1680/ macr.11.00120.

Aslani F and Nejadi S (2012) Cyclic constitutive model for highstrength concrete confined by ultra-high-strength and normal- strength transverse reinforcements. Australian Journal of Structural Engineering 12(2): 159-172.

BSI (2004) BS EN 1992-1-2: Eurocode 2: Design of concrete structures. Part 1.2: General rules: structural fire design. BSI, London, UK.

Carreira DJ and Chu KH (1985) Stress-strain relationship for plain concrete in compression. ACI Journal 82(6): 797-804.

Castillo C and Durani AJ (1990) Effect of transient high temperature on high strength concrete. ACI Materials Journal 87(1): 47-53.

Dias WPS, Khoury GA and Sullivan PJE (1990) The thermal and structural effects of elevated temperatures on the basic creep of hardened cement paste. Materials and Structures 23(6): 418-425.

Diederichs U (1987) Modelle zur beschreibung der betonverformung bei instantionaren temperaturen. In Abschlubkolloquium Bauwerke unter Brandeinwirkung. Technische Universitat, Braunschweig, Germany, pp. $25-34$.

Diederichs U, Ehm C, Weber A and Becker A (1987) Deformation behaviour of HRT concrete under biaxial stress and elevated temperatures. Proceedings of 9th International Conference on Structural Mechanics in Reactor Technology, Lausanne, Switzerland, Vol. H, paper H2/3.

Flynn DR (1999) Response of High Performance Concrete to Fire Conditions: Review of Thermal Property Data and Measurement Techniques. National Institute of Standards and Technology, Gaithersburg, MD, USA, NIST GCR 99-767, pp. 119-134.

Gawin D, Pesavento F and Schrefler BA (2004) Modelling of deformations of high strength concrete at elevated temperatures. Materials and Structures/Concrete Science and Engineering 37(4): 218-236.

Gross H (1975) High-temperature creep of concrete. Nuclear Engineering and Design 32(1): 129-147.

Hertz KD (2005) Concrete strength for fire safety design. Magazine of Concrete Research 57(8): 445-453.

Husem M (2006) The effects of high temperature on compressive and flexural strengths of ordinary and high-performance concrete. Fire Safety Journal 41(2): 155-163.

Khennane A and Baker G (1993) Uniaxial model for concrete under variable temperature and stress. ASCE Journal of Engineering Mechanics 119(8): 1507-1525.

Khoury GA, Grainger BN and Sullivan PJE (1985) Strain of concrete during first heating to $600^{\circ} \mathrm{C}$ under load. Magazine of Concrete Research 37(133): 195-215.

Khoury GA, Dias WPS and Sullivan PJE (1986) Deformation of concrete and cement paste loaded at constant temperatures from 140 to $724^{\circ}$ C. Materials and Structures 10(110): $97-$ 104.

Khoury GA, Majorana CE, Pesavento F and Schrefler BA (2002) Modeling of heated concrete. Magazine of Concrete Research 54(2): 77-101.

Kodur VKR and Harmathy TZ (2002) Properties of building materials. In SFPE Handbook of Fire Protection Engineering, 
3rd edn (DiNenno PJ (ed.)). National Fire Protection Agency, Quincy, MA, USA.

Kodur VKR, Dwaikat MMS and Dwaikat MB (2008) Hightemperature properties of concrete for fire resistance modeling of structures. ACI Materials Journal 105(5): 517-527.

Kordina K, Wydra W and Ehm C (1986) Analysis of the developing damage of concrete due to heating and cooling. Proceedings of Symposium of Evaluation and Repair of Fire Damage to Concrete (Harmathy TZ (ed.)), pp. 87-113.

Li $L$ and Purkiss JA (2005) Stress-strain constitutive equations of concrete material at elevated temperatures. Fire Safety Journal 40(7): 669-686.

Lie TT (1992) Structural Fire Protection. American Society of Civil Engineers, New York, NY, USA.

Malhotra HL (1982) Design of Fire-resisting Structures. Surrey University Press, London, UK.

Naus DJ (2006) The Effect of Elevated Temperature on Concrete Materials and Structures: A Literature Review. Office of Nuclear Regulatory Research, Washington, DC, USA, pp. 90-130.

Nielsen CV, Pearce CJ and Bicanic N (2002) Theoretical model of high temperature effects on uniaxial concrete member under elastic restraint. Magazine of Concrete Research 54(4): 239249.

Persson B (2003) Self-compacting concrete at fire temperature. TVBM-3110. Lund Institute of Technology, Lund, Sweden, p. 200.

Phan LT and Carino NJ (1998) Review of mechanical properties of HSC at elevated temperature. Journal of Materials in Civil Engineering 10(1): 58-64.

Phan LT and Carino NJ (2003) Code provisions for high strength concrete strength: Temperature relationship at elevated temperatures. Materials and Structures 36(256): 91-98.

Purkiss JA (1996) Fire Safety Engineering Design of Structures. Butterworth Heinemann, Oxford, UK.

Purkiss JA and Bali A (1988) The transient behaviour of concrete at temperature up to $800^{\circ} \mathrm{C}$. Proceedings of the 10th Ibausil, Weimar, Germany, Section 2/1, pp. 234-239.

Schneider U (1986) Modeling of concrete behavior at high temperatures. Proceedings of International Conference of Design of Structures Against Fire (Anchor RD, Malhotra HL and Purkiss JA (eds)). Elsivier Applied Science, London, UK, pp. $53-69$.

Schneider U (1988) Concrete at high temperatures: A general review. Fire Safety Journal 13(1): 55-68.

Shi X, Tan TH, Tan KH and Guo Z (2002) Concrete constitutive relationships under different stress-temperature paths. ASCE Journal of Structural Engineering 128(12): 1511-1518.

Sullivan PJE, Khoury GA and Grainger B (1983) Apparatus for measuring the transient thermal strain behaviour of unsealed concrete under constant load for temperatures up to $700^{\circ} \mathrm{C}$. Magazine of Concrete Research 2(125): 229-236.

Terro MJ (1998) Numerical modeling of the behavior of concrete structures in fire. ACI Structural Journal 95(2): 183-193.

Thelandersson S (1987) Modeling of combined thermal and mechanical action in concrete. Journal of Engineering Mechanics 113(6): 893-906.

Thienel KCh and Rostasy FS (1996) Transient creep of concrete under biaxial stress and high temperature. Cement and Concrete Research 26(9): 1409-1422.

Xiao J and Konig G (2004) Study on concrete at high temperature in China: An overview. Fire Safety Journal 39(1): 89-103.

\section{WHAT DO YOU THINK?}

To discuss this paper, please submit up to 500 words to the editor at www.editorialmanager.com/macr by 1 August 2013. Your contribution will be forwarded to the author(s) for a reply and, if considered appropriate by the editorial panel, will be published as a discussion in a future issue of the journal. 